\title{
A clean process for activator recovery during activated carbon production from waste biomass
}

\author{
Qian-Fang $\mathrm{Wu}^{\mathrm{a}, \mathrm{b}}$, Fu-Shen Zhang ${ }^{\mathrm{a}, *}$ \\ ${ }^{a}$ Research Center for Eco-Environmental Sciences, Chinese Academy of Sciences, 18 Shuangqing Road, Beijing 100085, China \\ ${ }^{\mathrm{b}}$ Graduate University of Chinese Academy of Sciences, Beijing 100039, China
}

\section{A R T I C L E I N F O}

\section{Article history:}

Received 10 May 2011

Received in revised form 15 August 2011

Accepted 25 August 2011

Available online 9 September 2011

\section{Keywords:}

Waste biomass

Activator recovery

Modified vacuum pyrolysis

Phenol adsorption

\begin{abstract}
A B S T R A C T
Chemical activation is a widespread method for activated carbon (AC) preparation, but the removal and recycle of activator from the carbon product are generally a nuisance process. In this study, an environmental benign process, called modified vacuum pyrolysis (MVP) process, was developed for AC production and simultaneous recovery of the activator. The process included two steps: (1) carbonization and activation stage in a vacuum condition; (2) zinc recovery stage in a special temperature and pressure range. In the MVP process, over $99.99 \%$ of the zinc used for activation was recovered in the form of zinc chloride and metallic zinc. The resultant ACs with basic and hydrophobic surface properties displayed higher adsorption capacity for phenol than that of carbons obtained by traditional pyrolysis method. The main merit of the MVP process was that there was no wastewater generation during the whole procedure. Consequently, the experimental data obtained in the present study provided scientific basis for zinc chloride recovery by vacuum pyrolysis during ACs production process.
\end{abstract}

(c) 2011 Elsevier Ltd. All rights reserved.

\section{Introduction}

The total amount of biomass resources is equivalent to 650 million TCE (ton of standard coal equivalent) per year in China [1]. This type of resource includes residues from agriculture and forestry, and the organic component of municipal and industrial wastes. Due to the absorption of carbon dioxide in its production process and less sulfur and ash content than coal, biomass is not only a clean but also a low-carbon fuel which becomes a sink for the greenhouse gases [2]. Currently, biomass energy is reviewed as one of the most promising renewable energy resources.

In the last decades, waste biomass energy was mainly consumed in rural areas of China by direct combustion. However, with social and economic development, a lot of rural people have been transferring into urban area gradually, and as a result the direct combustion of biomass has been decreasing in the recent years. Therefore, great interests have been paid for biomass to realize the value-added utilization by modern processing technologies, such as pyrolysis, gasification, and liquefaction [3]. However, the industrialization of bio-fuels production still confronts several challenges: (1) lower the cost of the bio-energy; (2) reduce the adverse environmental effect during the process of production and utilization of bio-fuels; (3) and produce a variety of energy and material products from biomass.

\footnotetext{
* Corresponding author. Tel./fax: +86 1062849515.

E-mail address: fszhang@rcees.ac.cn (F.-S. Zhang).
}

Activated carbons (ACs) are known as versatile materials which have been studied as adsorbents, catalysts and catalyst supports for different purposes. However, wildly using these materials tends to be expensive due to their high production costs. Many studies exploited waste biomass as precursors for ACs to reduce the production cost [4-6]. However, little attention has been paid for both simplifying and reducing the cost of the ACs production technology. The most commonly used methods for the preparation of ACs are based on so-called physical or chemical activation. A comparison of chemical activation against physical activation shows that chemical activation provides higher yield, lower temperature of activation (less energy costs), less activation time and, generally, higher development of porosity. The disadvantages of the chemical activation are the consumption of relatively expensive activating agents and the problems related to the washing and re-utilization of these agents [7]. As one of the commonly used activating agents, zinc chloride remains almost unchanged after chemical activation, thus it can be recycled by the traditional acid washing process. However, this recovery process is not only time consuming but also produces a large amount of wastewater, resulting in secondary pollution. Previous studies demonstrated that vacuum pyrolysis was an effective separation method in metallurgy for materials with different vapor pressure [8-10]. Furthermore, no off-gas and wastewater were produced during vacuum pyrolysis process thus this is an environmentally benign process. As for biomass conversion, vacuum pyrolysis was primarily used for bio-oil production [11-13]. In the recent years, researchers started to use vacuum 
pyrolysis for pretreatment or activation in ACs production, and significant improvements of ACs performance were achieved [14-20]. To the best of our knowledge, there is no report related to the activating agents recycling from ACs by vacuum pyrolysis. In this study, vacuum pyrolysis was applied for chemical recovery from ACs.

The objectives of this research were to: (1) examine the possibility of converting typical waste biomass in China into high quality ACs; (2) develop an environmental benign process for the ACs production achieving the recovery of chemical activator simultaneously; (3) optimize various parameters for the process and characterize the properties of the obtained AC.

\section{Experimental details}

\subsection{Materials}

Sawdust (pinewood) was used as the representative material. The raw material was obtained from a wood processing factory in Beijing suburb. Prior to use, the raw sawdust was oven dried for $48 \mathrm{~h}$ at $105^{\circ} \mathrm{C}$, then crushed and sieved to $<80$ meshes. The proximate and ultimate analyses of this material are shown in Table 1 . This waste may be considered as a good candidate for conversion to AC because of its relatively high carbon content and low ash. Chemical pure zinc chloride was purchased from Beijing Chemicals Company and used without any further purification.

\subsection{ACs preparation and activator recovery}

Activation was performed as follows: a certain amount of dried raw material was mixed with zinc chloride solution with impregnation ratio $1: 1$ (mass basis) for about $6 \mathrm{~h}$ at $80^{\circ} \mathrm{C}$, and then the resulting homogeneous slurry was dried at $110^{\circ} \mathrm{C}$ overnight. The activation of the impregnated material was conducted in a tubular furnace connected to cold traps. The cold traps were ice cooled for collecting volatiles and followed by a mechanical vacuum pump (ULVSC, GLD-051). The vacuum pump fitted with flow control devices could be adjusted from 0.1 to $100 \mathrm{kPa}$. In each run, the system was vacuumed to a certain pressure, and then heated to a desired temperature $\left(400-800^{\circ} \mathrm{C}\right)$ for a certain time at a fixed ramping rate. The reactor systems were cooled to room temperature under vacuum condition. The carbon and chemical samples collected from reactors and cold traps were weighed and kept for further treatments, respectively.

\subsection{Characterization of the ACS}

Zinc residues in samples before and after carbonization were analyzed by an inductively coupled plasma-optical emission spectrometry (ICP-OES, PerkinElmer, USA) after digesting with nitric acid, hydrofluoric acid and perchloric acid. There was $26.50 \mathrm{wt} . \%$ of zinc initially impregnated in the sawdust, and the amount of zinc recovered from ACs was calculated by:

Recovery rate of $\mathrm{Zn}(\%)=$ (mass of $\mathrm{Zn}$ impregnated

$$
\text { - mass of } \mathrm{Zn} \text { in the ACs)/(mass of } \mathrm{Zn} \text { impregnated) }
$$

Table 1

Proximate and ultimate analysis of the raw material.

\begin{tabular}{lrlr}
\hline \multicolumn{2}{l}{ Proximate (wt.\%, dry basis) } & Ultimate (wt.\%, dry and ash-free basis) \\
\hline Moisture & 4.02 & Carbon & 47.57 \\
Volatile matter & 76.64 & Nitrogen & 0.45 \\
Fixed carbon & 18.89 & Hydrogen & 6.57 \\
Ash & 0.45 & Oxygen (by difference) & 45.41 \\
\hline
\end{tabular}

Thermogravimetric analyses (TGA-2050, TA Instruments, USA) were carried out to investigate the thermal behavior of zinc chloride. About $40 \mathrm{mg}$ of chemical pure zinc chloride was heated from 30 to $900{ }^{\circ} \mathrm{C}$ at a ramping rate of $10^{\circ} \mathrm{C} \mathrm{min}^{-1}$ under flowing nitrogen. The pore structure characteristic of the activated carbon was determined using nitrogen as an adsorbate at $77 \mathrm{~K}$ in an automatic apparatus ASAP 2000 Micromeritics (USA). The BET surface area was calculated from the isotherm using the Brunauer-EmmettTeller (BET) equation. The crystalline structures of the ACs and condensates were examined by X-ray diffractometer (Philips PW, model 1700 , Netherlands) using $\mathrm{Cu} \mathrm{K} \alpha$ radiation at $40 \mathrm{kV}$ and $40 \mathrm{~mA}$ and scanning at a speed of $3^{\circ} \mathrm{min}^{-1}$.

The surface chemistry was analyzed by FT-IR spectroscopy, $\mathrm{pH}$ of the point of zero change $\left(\mathrm{pH}_{\mathrm{PZC}}\right)$ and SEM-EDX analysis. FT-IR spectra were determined in the range of $600-4000 \mathrm{~cm}^{-1}$ using potassium bromide pelletization method on a Nicolet Nexus 670 spectrophotometer (USA). The $\mathrm{pH}_{\mathrm{PZC}}$ of the carbon samples were measured using the $\mathrm{pH}$ drift method [21]. The $\mathrm{pH}$ of a solution of $0.01 \mathrm{M}$ sodium chloride was adjusted between $\mathrm{pH} 2$ and $\mathrm{pH} 12$ by adding either hydrochloride or sodium hydrate solution. A total of $0.10 \mathrm{~g}$ of activated carbon was added to $25 \mathrm{~mL}$ of the solution. After the $\mathrm{pH}$ had stabilized (typically after $24 \mathrm{~h}$ ), the final $\mathrm{pH}$ was recorded. The graphs of final $\mathrm{pH}$ versus initial $\mathrm{pH}$ were used to determine the points where the initial $\mathrm{pH}$ was equal to the final $\mathrm{pH}$. This point was taken as the $\mathrm{pH}_{\mathrm{PZC}}$ of the carbon. The surface morphology and elements were studied by scanning electron microscope - energy dispersive X-ray spectra (SEM-EDX, HITACHI S-3000 N, Japan).

\subsection{Adsorption experiment}

The adsorption of phenol from aqueous solution on the activated carbons was carried out at $25^{\circ} \mathrm{C}$ by using $0.10 \mathrm{~g}$ of carbons added into $100 \mathrm{~mL}$ of phenol solution with initial concentration of $100 \mathrm{mg} \mathrm{L}^{-1}$ in stoppered flasks. They were kept in a thermostat shaker bath at $25^{\circ} \mathrm{C}$ for 2 days, after which the equilibrium concentration was determined spectrophotometrically (UV-2450, Shimadzu, Japan) at the maximum absorbance wavelength of $269 \mathrm{~nm}$ [22].

\section{Results and discussion}

\subsection{Zinc recovery rate}

The effects of pressure and temperature on zinc recovery rate during the pyrolysis process are shown in Fig. 1. As can be seen, the zinc recovery rate dramatically increased with the temperature

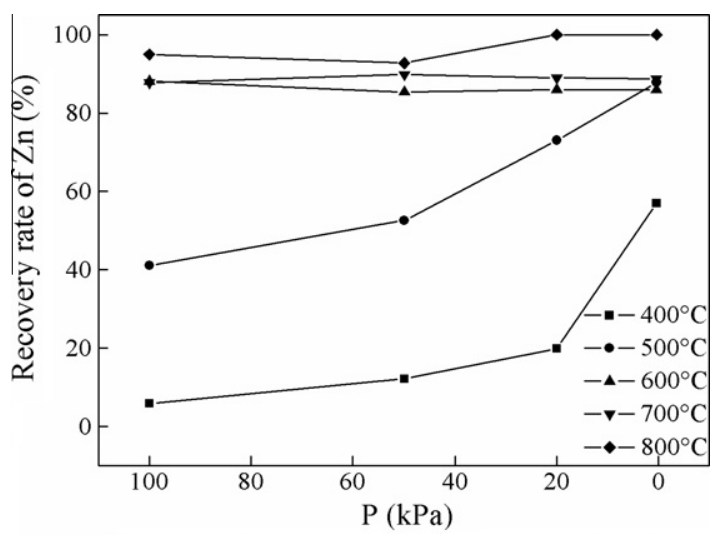

Fig. 1. Effects of pressure and temperature on zinc recovery rate (holding time $=30 \mathrm{~min}$, heating rate $=20^{\circ} \mathrm{C} \mathrm{min}^{-1}$ ). 
rising from 400 to $600{ }^{\circ} \mathrm{C}$. At the same time, lower system pressure below $50 \mathrm{kPa}$ could also effectively favor zinc recovery during this temperature range, e.g., the amount of zinc recovered at $500{ }^{\circ} \mathrm{C}$ is increased from about $40 \%$ at $100 \mathrm{kPa}$ to $90 \%$ at $1 \mathrm{kPa}$. According to the thermal behavior of pure zinc chloride under atmosphere pressure (Fig. 2), it can be seen that the evaporation of zinc chloride started at $400^{\circ} \mathrm{C}$, and almost all of them could evaporate into gaseous phase when the temperature is above $700{ }^{\circ} \mathrm{C}$ (about $0.02 \%$ ash remained). However, after impregnated with carbonaceous material, about $10 \%$ of zinc still remained in the carbonized materials at the temperature up to $700{ }^{\circ} \mathrm{C}$, and reducing system pressure had little effect on the zinc recovery rate during $600-700{ }^{\circ} \mathrm{C}$. The results showed that around $99.99 \%$ of zinc was recovered within $30 \mathrm{~min}$ by reducing system pressure below $20 \mathrm{kPa}$ at $800^{\circ} \mathrm{C}$.

Comparing Fig. 1 with Fig. 2, it can be seen that the complete extraction of activator after impregnation with carbonaceous materials requires higher temperature than that of pure zinc chloride. There might be several reasons hindering the activator recovery from AC products. On the one hand, the carbon materials after activation have abundant porous structures and functional groups, thus the physical and chemical adsorption between carbon and residual activator might inhibit effectively removing of activator in low temperatures. On the other hand, chemical reactions might happen to zinc chloride during the activation process and generate other substances. The carbonized samples obtained at various temperatures and pressures were analyzed by XRD analysis (Fig. 3). The formation of crystal zinc oxide was detected with the activation temperature above $400{ }^{\circ} \mathrm{C}$ (Fig. 3a). The higher boiling point $\left(2360^{\circ} \mathrm{C}\right)$ and decomposition temperature $\left(1975^{\circ} \mathrm{C}\right)$ of zinc oxide is one of the reasons for hindering complete recovery of zinc from carbon products below $800^{\circ} \mathrm{C}$. Meanwhile, the amount of zinc chloride detected in the carbon products at $700{ }^{\circ} \mathrm{C}$ indicates that there are strong adsorption effects between the carbon material and the activator (Fig. 3a). Rising temperature from 400 to $600{ }^{\circ} \mathrm{C}$ at $50 \mathrm{kPa}$ (Fig. 3a) or lower pressure from 100 to $20 \mathrm{kPa}$ at $500{ }^{\circ} \mathrm{C}$ (Fig. 3b) both increased the intensities of diffraction peaks of zinc oxide, which is due to the enhancement of crystallization. With the disappearance of zinc oxide peaks from the AC obtained at $800^{\circ} \mathrm{C}, 20 \mathrm{kPa}$, metallic zinc could be detected in the condensate, otherwise, zinc chloride and its hydrates could be mainly collected during $400-600{ }^{\circ} \mathrm{C}$ in the condensers (Fig. 3c). It can be deduced that the amount of zinc recovered below $600{ }^{\circ} \mathrm{C}$ mainly caused by the evaporation of zinc chloride. Lowering pressure from 100 to $20 \mathrm{kPa}$ could reduce the boiling point of zinc chloride from 532 to $432{ }^{\circ} \mathrm{C}$, thus lowering pressure enhanced the zinc recovery greatly below $600{ }^{\circ} \mathrm{C}$. When it comes to higher temperatures, zinc oxide became the major chemical residue in the ACs. Then the zinc

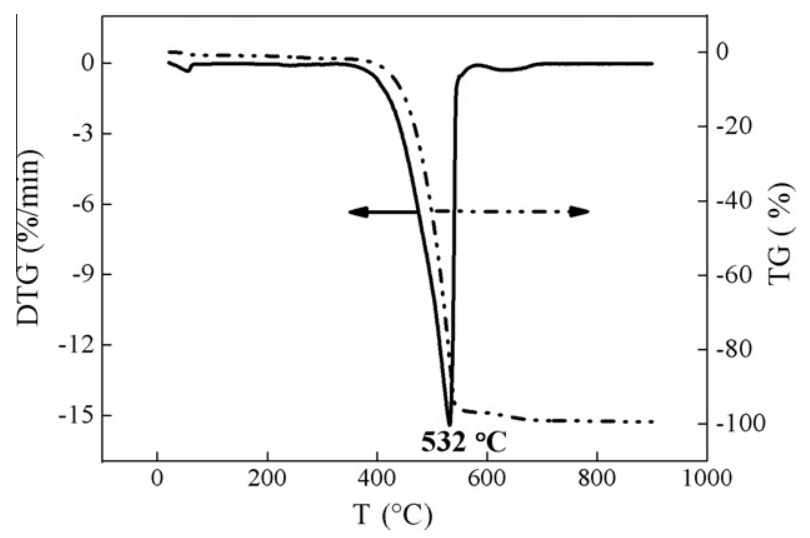

Fig. 2. Thermogravimetric analyses (TGA) in a nitrogen atmosphere of zinc chloride (heating rate $=10^{\circ} \mathrm{C} \mathrm{min}^{-1}$ ). recovery process involves the redox reaction between zinc oxide and carbon and the evaporation of the metallic zinc, which is much more complex and needs more stringent conditions. Detailed discussion is in the following text. Due to the profound discrepancy of condensing temperature between metallic zinc and zinc chloride, they will be condensed at different temperature regions of the collector, thus effective separation of them could be achieved. During the pyrolysis process, the following chemical reactions might occur: firstly, zinc chloride hydrolyzed during the impregnation process. Thermal treatment decomposed the hydrates of zinc chloride, causing the formation of volatile hydrochloric acid [23]. Meanwhile, an acid-base cement like material $\left(\mathrm{Zn}_{2} \mathrm{OCl}_{2} \cdot 2 \mathrm{H}_{2} \mathrm{O}\right)$ was found in the ACs at $400-500{ }^{\circ} \mathrm{C}$ (Fig. 3). The cement like material was mainly in amorphous phase with a little crystalline phase $[24,25]$. When the temperature was above $400{ }^{\circ} \mathrm{C}$, the compounds decomposed into volatile zinc chloride, steam, and solid zinc oxide (Eq. (2)). Raising temperature from 400 to $600{ }^{\circ} \mathrm{C}$ or lowering pressure from 100 to $20 \mathrm{kPa}$ both promoted the evaporation of zinc chloride, thus enhanced the formation and crystallization of zinc oxide. Finally, the residual zinc oxide was removed by carbothermal process $[26,27]$ shown in the following equation:

$$
\begin{aligned}
& 2 \mathrm{ZnCl}_{2}+3 \mathrm{H}_{2} \mathrm{O} \rightarrow \mathrm{Zn}_{2} \mathrm{OCl}_{2} \cdot 2\left(\mathrm{H}_{2} \mathrm{O}\right)+2 \mathrm{HCl} \uparrow \quad 300-400{ }^{\circ} \mathrm{C} \\
& \mathrm{Zn}_{2} \mathrm{OCl}_{2} \cdot 2\left(\mathrm{H}_{2} \mathrm{O}\right) \rightarrow \mathrm{ZnCl}_{2} \uparrow+\mathrm{ZnO}+2 \mathrm{H}_{2} \mathrm{O} \uparrow \quad 400-600{ }^{\circ} \mathrm{C} \\
& \mathrm{ZnO}+\mathrm{C} \rightarrow \mathrm{Zn} \uparrow+\mathrm{CO} \uparrow \quad>800{ }^{\circ} \mathrm{C}
\end{aligned}
$$

According to previous reports, carbothermal reduction of zinc oxide and effective recovery of zinc could be achieved at about $1200-1300{ }^{\circ} \mathrm{C}[28]$, and moreover, Mariusz Grabda, etc. proposed that the reaction temperature could decline to around $1000^{\circ} \mathrm{C}$ by mixture of waste polyvinyl chloride or tetrabromobisphenol A with the reactors $[29,30]$. In this study, when system pressure was below $20 \mathrm{kPa}$, almost total zinc recovery could be achieved at $800{ }^{\circ} \mathrm{C}$, thus lowering system pressure had not only declined the carbothermal reaction temperature but also enhanced the metal evaporation velocity [10]. Thermodynamic analysis of the carbothermal reaction further demonstrates this point (shown in the following equation):

$$
\Delta G=\Delta G^{\theta}+\mathrm{RT} \ln \left[P_{\mathrm{Zn}} / P^{0}\right]\left[P_{\mathrm{CO}} / P^{0}\right]
$$

where $\Delta G$ is the Gibbs free energy at a certain temperature (J), $R$ the universal gas constant, $T$ treatment temperature $(\mathrm{K})$ and $P$ system pressure $(\mathrm{Pa}), P^{0}$ the saturated pressure of metallic zinc at a certain temperature $(\mathrm{Pa})$.

The redox reaction could take place when $\Delta G<0$. The reaction temperature could be reduced from $948^{\circ} \mathrm{C}$ at $100 \mathrm{kPa}$ to $800{ }^{\circ} \mathrm{C}$ when the system pressure decreased to $20 \mathrm{kPa}$, and at the same time the evaporation velocity of metallic zinc increases sharply with the pressure lower than the saturated vapor pressure at $800{ }^{\circ} \mathrm{C}$ (about $30 \mathrm{kPa}$ ). However, with further decreasing of the pressure to $0.2 \mathrm{kPa}\left(\Delta G=0 \mathrm{~J}, T=522^{\circ} \mathrm{C}\right)$, few metallic zinc was obtained in the condenser within $30 \mathrm{~min}$ at $522^{\circ} \mathrm{C}$, indicating that the reduced zinc could not be effectively recovered. Therefore, the key factor restricting zinc recovery rate below $800{ }^{\circ} \mathrm{C}$ was the evaporating velocity of the reduced zinc. This could be attributed to the fact that the saturated vapor pressure of metallic zinc is significantly reduced at lower temperature, e.g., at $800{ }^{\circ} \mathrm{C}$, the saturated vapor pressure of metallic zinc is about $30 \mathrm{kPa}$, while at $500{ }^{\circ} \mathrm{C}$ the saturated vapor pressure is merely $0.018 \mathrm{kPa}$. Moreover, the activated carbon with large surface area also inhibited zinc evaporation at low temperature.

From the theoretical and experimental results stated above, it could be concluded that there are two steps included in the chemicals recovery process, namely zinc chloride evaporation process 
(a)

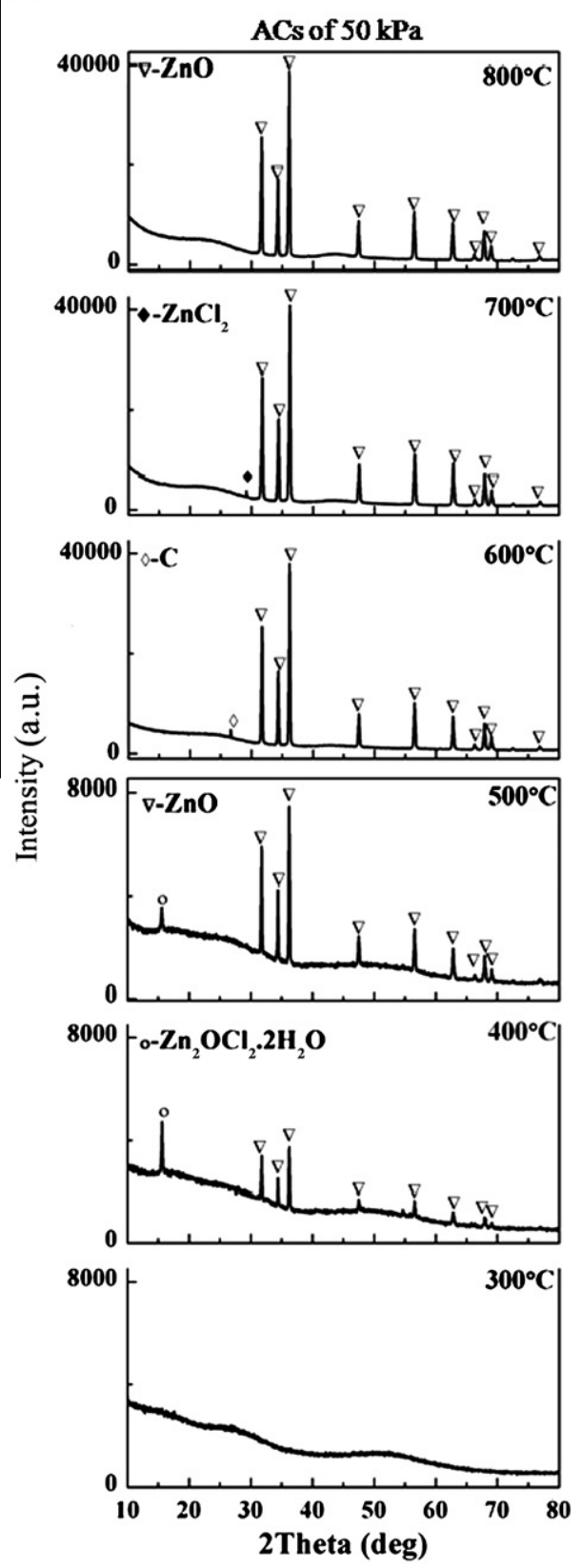

(b)

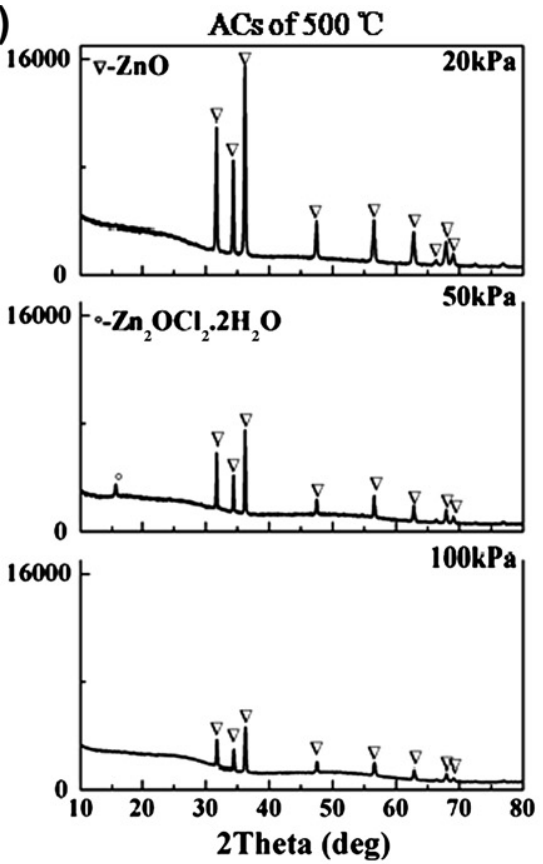

(c)

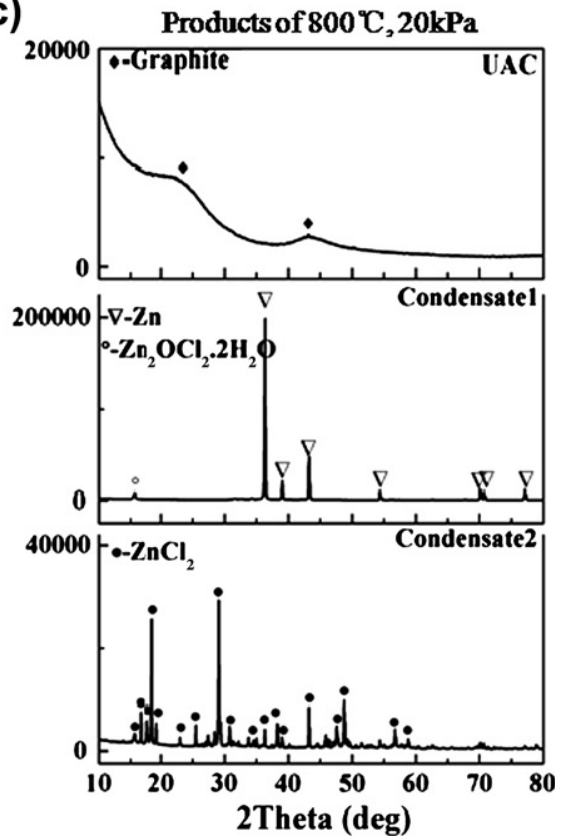

Fig. 3. XRD patterns of condensates (c) and ACs obtained at different temperatures (a) and pressures (b) (holding time $=30 \mathrm{~min}$, heating rate $=20{ }^{\circ} \mathrm{C}$ min ${ }^{-1}$ ).

below $600{ }^{\circ} \mathrm{C}$ and carbothermal reduction of zinc oxide above $800^{\circ} \mathrm{C}$, only when the pressure was less than $20 \mathrm{kPa}$ the zinc oxide could be effectively removed within $30 \mathrm{~min}$ at $800^{\circ} \mathrm{C}$. Compared with other pyrometallurigical methods for zinc recovery from zinc oxide, vacuum pyrolysis not only consumed less energy but also obtained higher removal efficiency.

\subsection{Characterization of the obtained carbons}

The effects of temperature and pressure on the bulk properties and the yields of the obtained products are presented in Fig. 4. In the pressure range studied in this paper $\left(1-100 \mathrm{kPa}\right.$, at $\left.500{ }^{\circ} \mathrm{C}\right)$, the maximum surface area, total pore volume and yield of carbon are observed at $50 \mathrm{kPa}$, and the minimum of the average pore diameter also occurred at this point. It was demonstrated that decreasing system pressure in a certain range can reduce the oxygen in the system and the residence time of organic vapor. Low residence time of organic vapor limits the secondary reactions which form carbonaceous deposits on the surface and in the pores of the ACs [15]. The surface area and total pore volume decline sharply with pressure decreasing from 50 to $20 \mathrm{kPa}$, then hold steady when the pressure less than $20 \mathrm{kPa}$ (Fig. 4a). However, a continuous yield decrease and pore size increase can be observed with pressure decreasing from 50 to $1 \mathrm{kPa}$ (Fig. $4 \mathrm{~b}$ ), which is attributed to the vigorous volatilization of pyrolysis vapor. In the temperature range studied in this paper $\left(400-800^{\circ} \mathrm{C}\right.$, at $\left.50 \mathrm{kPa}\right)$, the surface area, pore volume and yield continuously decrease while the average pore size fluctuates with temperature increasing. The dramatic shrinkage of the porosity was coincident with the violent evaporation of zinc chloride with the effects of pressure and temperature 

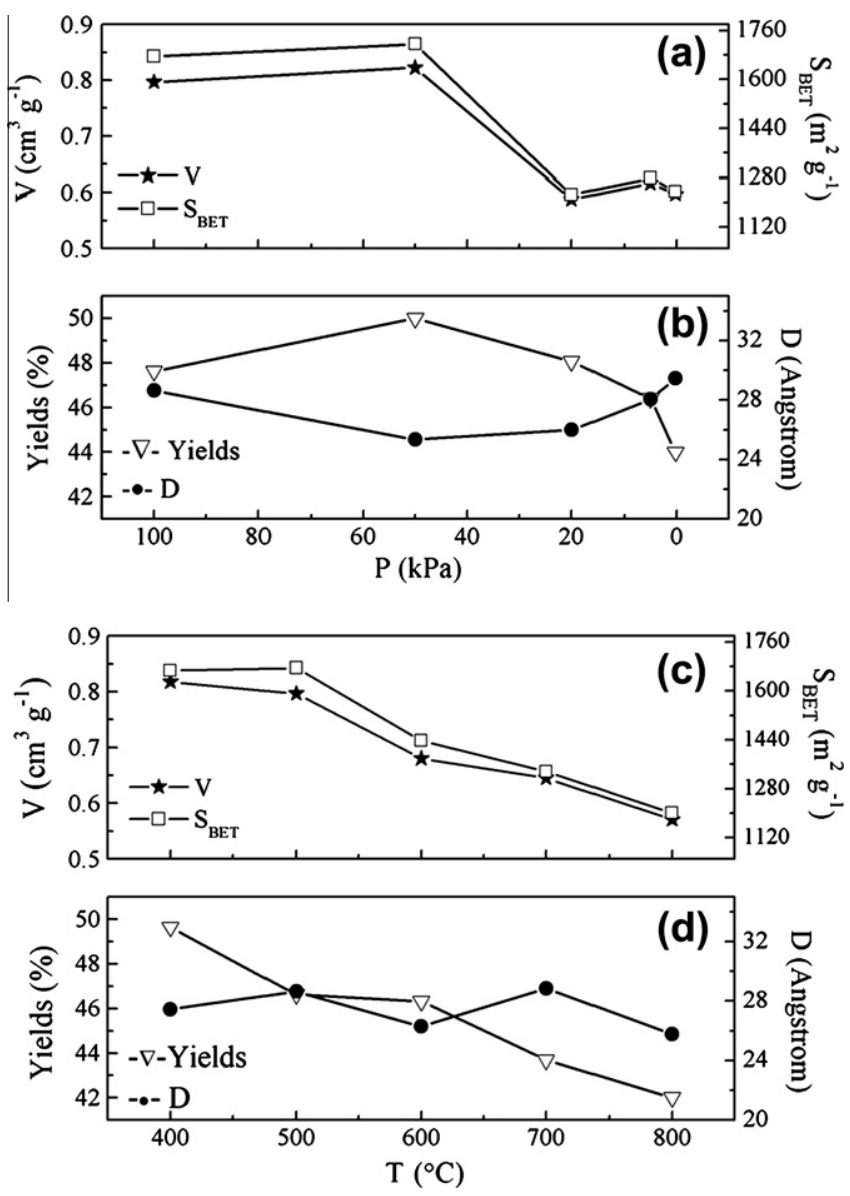

Fig. 4. Effects of pressure and temperature on surface properties and carbon yields of the activated carbons (holding time $=30 \mathrm{~min}$, heating rate $=20^{\circ} \mathrm{C} \mathrm{min}^{-1}$ ). $S_{\mathrm{BET}}=\mathrm{BET}$ surface area, $V=$ total pore volume, Yields $=$ carbon yields, $D=$ average pore diameter.

shown in Fig. 2. In a previous report, it was claimed that zinc chloride worked as dehydration reagent and restricted the formation of tar and promoted the charring of the carbon below the carbonization temperature of the precursor [31]. Thus, excessive evaporation of zinc chloride prior to the carbonization could decrease the activation effect resulting in the decrease of specific surface area and total pore volume. Also, the vigorous volatilization of pyrolysis vapor would destroy the microporous structure and lower the yields of AC shown in Fig. 4b. It can be concluded from Fig. 4 that the maximum of specific surface area, total pore volume and carbon yield of the AC were obtained at $50 \mathrm{kPa}$ and $400{ }^{\circ} \mathrm{C}$, which is optimum for AC production.

Combining the effects of temperature and system pressure on zinc recovery and AC quality (Fig. 1 and Fig. 4), it can be concluded that the suitable temperature and pressure for the AC production is $400{ }^{\circ} \mathrm{C}$ and $50 \mathrm{kPa}$, where microporous carbon with high specific surface area, total pore volume and carbon yield can be obtained. However, the effective domain for the zinc recovery is $800^{\circ} \mathrm{C}$ and $<20 \mathrm{kPa}$, which is applicable for zinc oxide reduction and zinc removal in an appropriate time span. It can be seen from Fig. 4 that decreasing the system pressure from 20 to $1 \mathrm{kPa}$ had little effects on the porosity of ACs, but significant heat shrinkage of the porosity could be observed by increasing the temperature from 400 to $800{ }^{\circ} \mathrm{C}$, thus applying $1 \mathrm{kPa}$ at $800^{\circ} \mathrm{C}$ could effectively increase the evaporation rate of the chemicals, and then decrease the holding time of ACs at high temperature. It can be observed by the white smoke in the condensers that the removal and evaporation of residual zinc only lasts for a few minutes. In order to completely remove zinc chloride and simultaneously obtain highly quality AC, the vacuum pyrolysis was modified. Firstly, a medium system pressure $(50 \mathrm{kPa})$ was applied at temperature rising period ranging from 30 to $400{ }^{\circ} \mathrm{C}$ and kept at $400{ }^{\circ} \mathrm{C}$ for $1 \mathrm{~h}$. During this stage the carbon structure was modified and the porosity increased. Secondly, low system pressure $(1 \mathrm{kPa})$ was applied at temperature rising period from 400 to $800{ }^{\circ} \mathrm{C}$ and kept for $10 \mathrm{~min}$. The results indicated that the zinc content of the AC obtained by modified vacuum pyrolysis (MVP) was less than $0.01 \mathrm{wt} . \%$, meeting the standard for ACs application on drinking water treatment [32]. Furthermore, the AC obtained by MVP process had higher specific surface area, total pore volume and AC yield $\left(1350 \mathrm{~m}^{2} \mathrm{~g}^{-1}\right.$, $0.64 \mathrm{~cm}^{3} \mathrm{~g}^{-1}$ and $42.54 \mathrm{wt}$.\% respectively) than those of ACs obtained by traditional vacuum pyrolysis at $800^{\circ} \mathrm{C}$. Therefore, MVP is an effective way to recycle chemicals and obtain highly porous ACs.

Fig. 5 compares the FTIR spectra of the ACs prepared by MVP process and traditional process $\left(500{ }^{\circ} \mathrm{C}\right.$, nitrogen atmosphere). The washed and unwashed ACs obtained by traditional process are denoted as 500-AW and 500-UW, respectively. As can be seen from Fig. 1, about 60 wt.\% of zinc remained in the 500-UW. Thus significant differences can be observed from FTIR spectra between 500-UW and 500-AW. The strong absorbance peaks appeared at 1615 and $3571 \mathrm{~cm}^{-1}$ in 500-UW are mainly due to the chemicals remained in the carbonized material. After removing chemical activating agents by acid washing the functional groups that are often observed in ACs in FTIR analysis, namely alkenes, esters, aromatic, ketones, alcohol, hydroxyl and carboxyl, are found on the surface of 500-AW. With the help of the literatures, the bands at 3200$3600 \mathrm{~cm}^{-1}$ and $950-1300 \mathrm{~cm}^{-1}$ are assigned to the $\mathrm{O}-\mathrm{H}$ and the $\mathrm{C}-\mathrm{O}$ stretching vibration mode of hydroxyl functional groups including $\mathrm{H}$ bonding and indicating the presence of phenol, esters, ethers groups. The bands at $2800-3000 \mathrm{~cm}^{-1}$ indicate the presence of aliphatic $\mathrm{C}-\mathrm{H}$ stretching, and at $1687 \mathrm{~cm}^{-1}$ indicates stretching of conjugated $\mathrm{C}=\mathrm{C}$ or aromatic-oxygen bond in aromatic ether. The bands around $1434 \mathrm{~cm}^{-1}$ are assigned to $\mathrm{C}-\mathrm{H}$ or $-\mathrm{CH}_{2}$ groups, which are overlapped [33]. Those groups detected from the ACs surface are mainly oxygen-containing acidic groups.

On the other hand, for the ACs obtained by MVP process, due to the complete removal of activators, there are little differences between the FTIR spectra before or after acid washing, e.g., only a little increase of intensity of $3255 \mathrm{~cm}^{-1}$ is observed after acid washing process, attributing to the hydrogen-bonded groups. However, the FT-IR spectrum of AC obtained from MVP process is quite different from that of carbon obtained from traditional pyrolysis. A remarkable decrease in the intensity of $3380 \mathrm{~cm}^{-1}$, and the disappearance of bands at $1014,1287,1687 \mathrm{~cm}^{-1}$ indicate that the MVP treatment decomposes the oxygen functional groups in the carbons, and this could be attributed to the decomposition of the carboxylic acid groups and partial intermolecular rearrangements to form lactone groups. The appearance of absorbance peaks on the range of $1700-1780 \mathrm{~cm}^{-1}$ indicating the presence of ketones and aldehydes also confirm the inference. The band around $1516 \mathrm{~cm}^{-1}, 734 \mathrm{~cm}^{-1}, 861 \mathrm{~cm}^{-1}$ attributed to aromatic stretching are clearly observed, suggesting the AC becomes increasing polyaromatic after MVP treatment. The surface functional groups play an important role in many properties of ACs, in particular their wetting and adsorption behavior. Chemical activation always results in oxygen-containing polar groups being covalently bound to the carbon surface besides the development of porous structure in the material. Most of the surface oxides are acidic, and they provide hydrophilic sites. Therefore, the adsorption capacity for polar and basic materials can be significantly improved. While treating ACs under MVP process has selectively removed some of these functional groups. Carbons with a low oxygen content exhibit basic surface properties and an anion 


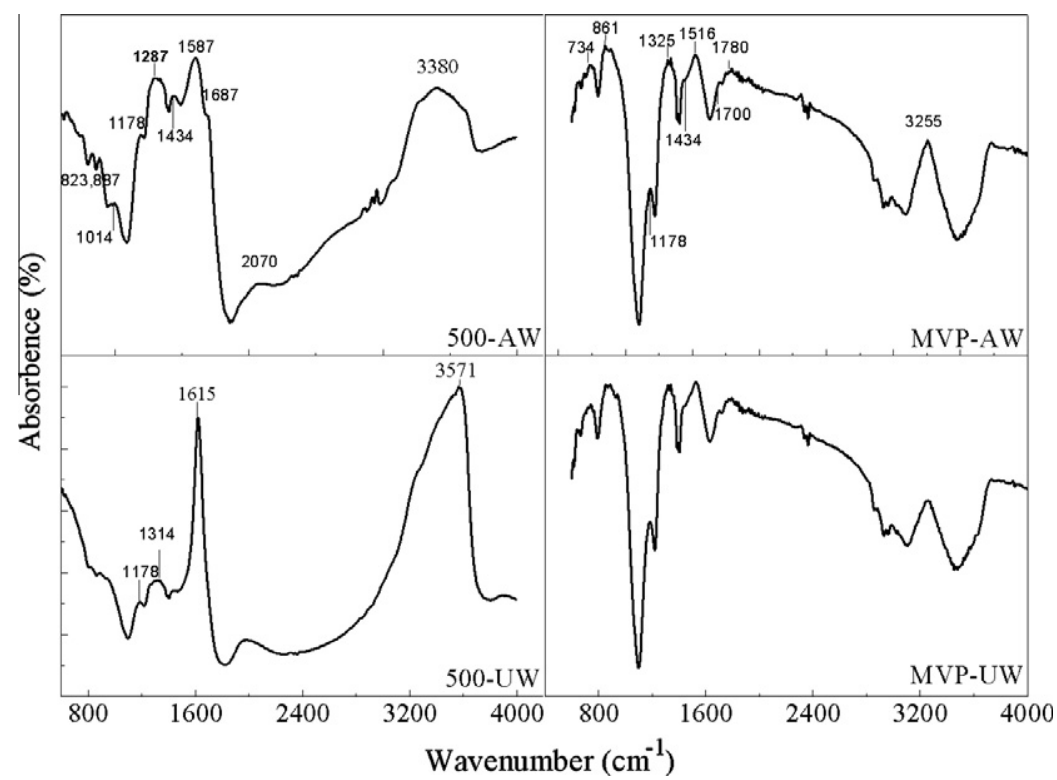

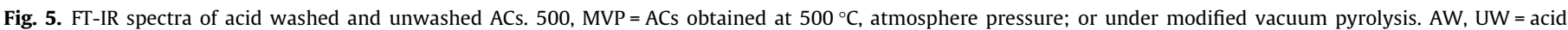
washed or unwashed.

Table 2

Comparisons of the ACs obtained by MVP process and traditional process.

\begin{tabular}{|c|c|c|c|c|c|c|c|c|c|}
\hline Sample & Wastewater $\left(\mathrm{Lg}^{-1}\right)$ & Zn (wt.\%) & $\mathrm{Cl}$ (wt.\%) & Ash (wt.\%) & $V_{\mathrm{T}}\left(\mathrm{cm}^{3} \mathrm{~g}^{-1}\right)$ & $V_{\text {Mic }}\left(\mathrm{cm}^{3} \mathrm{~g}^{-1}\right)$ & $S\left(\mathrm{~m}^{2} \mathrm{~g}^{-1}\right)$ & $\mathrm{pH}_{\text {PZI }}$ & Phenol $^{\mathrm{d}}\left(\mathrm{mg} \mathrm{g}^{-1}\right)$ \\
\hline $500-\mathrm{AW}^{\mathrm{a}}$ & 2 & $<0.01$ & 2.35 & 0.21 & 0.79 & 0.62 & 1675 & 5.37 & 166 \\
\hline MVP-AW & 1 & $<0.01$ & 1.82 & 0.39 & 0.66 & 0.59 & 1359 & 7.01 & 214 \\
\hline MVP-UW ${ }^{c}$ & - & $<0.01$ & 0.08 & 3.85 & 0.64 & 0.58 & 1350 & 7.25 & 237 \\
\hline
\end{tabular}

a Activated carbon obtained at $500{ }^{\circ} \mathrm{C}$ under atmosphere pressure after acid washing.

b Activated carbon obtained by modified vacuum pyrolysis after acid washing.

c Activated carbon obtained by modified vacuum pyrolysis before acid washing.

d Phenol adsorption capacity obtained at $25^{\circ} \mathrm{C}$.

exchange behavior, which could enhance the adsorption capacity of acidic contaminants [36].

The higher value of $\mathrm{pH}_{\mathrm{PZI}}$ of MVP-UW (shown in Table 2) also indicates that the basicity and/or hydrophobic surface properties of the carbon can be obtained by removing the acidic oxygencontaining surface groups by the MVP process. From Table 2, it can be seen that removing of residual zinc from a gram of AC by traditional acid washing process will produce about $2 \mathrm{~L}$ of wastewater containing various metal elements. Thus the treatment of the wastewater was difficult and costly. Alternatively, the MVP process can effectively remove zinc from ACs, and at the same time the activator recycled could be used directly, moreover, no wastewater was produced.

\subsection{Phenol adsorption}

The phenol adsorption capacities of ACs obtained by MVP process and traditional pyrolysis are displayed in Table 2 . It can be seen that ACs obtained from MVP process display superior adsorption capacity for phenol than that of 500-AW. At the same time, demineralization of the carbons by acid washing also had a negative effect on phenol adsorption. It has been reported that the most important characteristics of AC in the adsorption of organic compounds were pore size distribution, surface chemistry, and mineral matter content [34]. Phenol is a small $(10 \AA)$ and weakly acidic molecule, which tends to be adsorbed on the microporous and basic ACs [35,37]. However, the highest phenol adsorption (237 $\mathrm{mg} \mathrm{g}^{-1}$ ) was obtained by MVP-UW which has lowest micropore volume but highest $\mathrm{pH}_{\mathrm{PZI}}$ value among the other ACs compared (Table 2). Thus it can be concluded that the basicity surface chemistry played a decisive role in the phenol adsorption process in this study, which was consistent with previous reports [22]. It has been reported that the basic and hydrophobic ACs are more stable at ambient conditions [36], and have predominant adsorption capacity for non-polar and acidic materials [37]. The MVP increased the phenol adsorption capacity by removing the acidic oxygen-containing surface groups, while the acid washing process showed the opposite effect. It has been found that the demineralization treatments with hydrochloride lead to small amount of chloride adsorbed on the surface of the carbons, which was detected by EDX and shown in Table 2. The adsorbed chloride would decrease the surface basicity of the carbons by localizing the electrons, thus inhibiting the formation of electron donor-acceptor complexes with phenol [22]. Therefore, MVP process could not only recycle the chemicals without any wastewater generation, but also modified the surface chemistry for phenol adsorption.

\section{Conclusions}

This study developed an environmentally benign process, called modified vacuum pyrolysis (MVP) process, for AC preparation from waste biomass with the activating agent recycling simultaneously. Using MVP, $99.99 \%$ of zinc was recovered from ACs during the production process without any wastewater production. The temperature and pressure were two key parameters affecting the recovery rate of the chemicals and the porosities of the resultant AC. The resultant $A C$ has superior physical properties with BET surface area $1350 \mathrm{~m}^{2} \mathrm{~g}^{-1}$ and pore volume $0.645 \mathrm{~cm}^{3} \mathrm{~g}^{-1}$, respectively. Further- 
more, the surface chemistry of the AC tended to be basic and hydrophobic, and this resulted in a higher adsorption capacity for phenol than that of AC obtained by the traditional pyrolysis process. Therefore, the MVP process is a potential alternative for zinc chloride chemical activators removing and recycling during AC production from waste biomass.

\section{Acknowledgments}

This work was made possible by the financial supports from the National Water Pollution Control and Management Program (2009ZX07212-002), the National Basic Research Program (2007 CB407303) and the National Key Technology R\&D Program (2008BAC32B03).

\section{References}

[1] Zhou H. Discussion on development strategy and policy measure for renewable energy during tenth five-year-plan. In: Proceeding: clean energy technology seminar. Beijing, China; 2001. p. 1-5.

[2] Li JF, Hu RQ. Sustainable biomass production for energy in China. Biomass Bioenergy 2003;25:483-99.

[3] Chang J, Leung DYC, Wu CZ, Yuan ZH. A review on the energy production, consumption, and prospect of renewable energy in China. Renew Sust Energy Rev 2003;7:453-68.

[4] Ioannidou O, Zabaniotou A. Agricultural residues as precursors for activated carbon production - a review. Renew Sust Energy Rev 2007;11:1966-2005.

[5] Liu ZG, Zhang FS, Wu JZ. Characterization and application of chars produced from pinewood pyrolysis and hydrothermal treatment. Fuel 2010;89:510-4.

[6] Ioannidou OA, Zabaniotou AA, Stavropoulos GG, Islam MA, Albanis TA. Preparation of activated carbons from agricultural residues for pesticide adsorption. Chemosphere 2010;80:1328-36.

[7] Eletskii PM, Yakovlev VA, Fenelonov VB, Parmon VN. Texture and adsorptive properties of microporous amorphous carbon materials prepared by the chemical activation of carbonized high-ash biomass. Kinet Catal 2008;49:708-19.

[8] Labaj J, Oleksiak B, Siwiec G. Analysis of the options of copper removal from liquid iron by evaporation. Metalurgija 2011;50:173-5.

[9] Zhan L, Xu ZM. Application of vacuum metallurgy to separate pure metal from mixed metallic particles of crushed waste printed circuit board scraps. Environ Sci Technol 2008;42:7676-81.

[10] Chen MJ, Zhang FS, Zhu JX. Lead recovery and the feasibility of foam glass production from funnel glass of dismantled cathode ray tube through pyrovacuum process. J Hazard Mater 2009;161:1109-13.

[11] Lu Q, Li WZ, Zhu XF. Overview of fuel properties of biomass fast pyrolysis oils. Energy Convers Manage 2009;50:1376-83.

[12] Mohan D, Pittman CU, Steele PH. Pyrolysis of wood/biomass for bio-oil: a critical review. Energy Fuel 2006;20:848-89.

[13] Xu SJ, Lie J, Qiao GJ, Wang HJ, Lu TJ. Pore structure control of mesoporous carbon monoliths derived from mixtures of phenolic resin and ethylene glycol. Carbon 2009;47:2103-11.

[14] Lua A, Yang T. Properties of pistachio-nut-shell activated carbons subjected to vacuum pyrolysis conditions. Carbon 2004;42:224-6.
[15] Juan Y, Qiu KQ. Preparation of activated carbon by chemical activation under vacuum. Environ Sci Technol 2009;43:3385-90.

[16] Lua AC, Yang T. Effects of vacuum pyrolysis conditions on the characteristics of activated carbons derived from pistachio-nut shells. J Colloid Interf Sci 2004;276:364-72.

[17] Darmstadt H, Garcia-Perez M, Chaala A, Cao NZ, Roy C. Co-pyrolysis under vacuum of sugar cane bagasse and petroleum residue - properties of the char and activated char products. Carbon 2001;39:815-25.

[18] Lua AC, Yang T. Characteristics of activated carbon prepared from pistachionut shell by zinc chloride activation under nitrogen and vacuum conditions. J Colloid Interf Sci 2005;290:505-13.

[19] Ismadji S, Sudaryanto Y, Hartono SB, Setiawan LEK, Ayucitra A. Activated carbon from char obtained from vacuum pyrolysis of teak sawdust: pore structure development and characterization. Bioresource Techno 2005;96:1364-9.

[20] Cao NZ, Darmstadt H, Roy C. Activated carbon produced from charcoal obtained by vacuum pyrolysis of softwood bark residues. Energy Fuel 2011;15:1263-9.

21] Lopez-Ramon MV, Stoeckli F, Moreno-Castilla C, Carrasco-Marin F. On the characterization of acidic and basic surface sites on carbons by various techniques. Carbon 1999;37:1215-21.

[22] Morenocastilla C, Riverautrilla J, Lopezramon MV, Carrascomarin F. Adsorption of some substituted phenols on activated carbons from a bituminous coal. Carbon 1995;33:845-51.

[23] Fritz Feigl AC. Some applications of fusion reactions with zinc chloride in inorganic spot test analysis. Microchim Acta 1956;44:1310-6.

[24] Nicholson JW, Parker L. The chemistry of cements formed between zinc oxide and aqueous zinc chloride. J Mater Sci 1998;33:2251-4.

[25] Wilson AD, Nicholson JW. Acid-base cements: their biomedical and industrial applications. New York: Cambridge University Press; 1993.

[26] Greenwood NNE. Chemistry of the elements. Oxford: ButterworthHeinemann; 1997. ISBN 0-7506-3365-4.

[27] Kim E, Cho S, Lee J. Kinetics of the reactions of carbon containing zinc oxide composites under microwave irradiation. Meals Mater Int 2009;15:1033-7.

[28] Antrekowitsch J, Antrekowitsch $\mathrm{H}$. Hydrometallurgically recovering zinc from electric arc furnace dusts. Jom-J Min Metal Mater Soc 2001;53:26-8.

[29] Grabda M, Oleszek-Kudlak S, Shibataa E, Nakamura T. Vaporization of zinc during thermal treatment of $\mathrm{ZnO}$ with tetrabromobisphenol A (TBBPA). J Hazard Mater 2011;187:473-9.

[30] Lee GS, Song YJ. Recycling EAF dust by heat treatment with PVC. Miner Eng 2007;20:739-46.

[31] Hayashi J, Kazehaya A, Muroyama K, Watkinson AP. Preparation of activated carbon from lignin by chemical activation. Carbon 2000;38:1873-8.

[32] National standards. Wooden activated carbon for water purification. G.T. 13803.2-1999; 1999

[33] Fu P, Hu S, Xiang J, Sun LS, Li PS, Zhang JY, et al. Pyrolysis of maize stalk on the characterization of chars formed under different devolatilization conditions. Energy Fuel 2009;23:4605-11.

[34] Dias JM, Alvim-Ferraz MCM, Almeida MF, Rivera-Utrilla J, Sanchez-Polo M. Waste materials for activated carbon preparation and its use in aqueous-phase treatment: a review. J Environ Manage 2007;85:833-46.

[35] Hu ZH, Srinivasan MP, Ni YM. Novel activation process for preparing highly microporous and mesoporous activated carbons. Carbon 2001;39: 877-86

[36] Verma SK, Walker PL. Carbon molecular-sieves with stable hydrophobic surfaces. Carbon 1992;30:837-44.

[37] Qiang D. Characterization of adsorbent-adsorbate interaction mechanisms on activated carbons. America: Ph.D thesis of University of Iowa; 2003. p. 40-4. 